\title{
Comparison of Metacognition Profiles between Male and Female Mathematics Students in Interpreting of Definite Integral Concepts
}

\author{
La Misu*, Mohamad Salam \\ Department of Mathematics, Universitas Halu Oleo, Jl. H.E.A. Mokodompit No. 1, Kendari 93231, Indonesia
}

Received October 30, 2020; Revised December 9, 2020; Accepted December 18, 2020

\section{Cite This Paper in the following Citation Styles}

(a): [1] La Misu, Mohamad Salam, "Comparison of Metacognition Profiles between Male and Female Mathematics Students in Interpreting of Definite Integral Concepts, "Universal Journal of Educational Research, Vol. 8, No. 12B, pp. 8313-8323, 2020. DOI: 10.13189/ujer.2020.082636.

(b): La Misu, Mohamad Salam (2020). Comparison of Metacognition Profiles between Male and Female Mathematics Students in Interpreting of Definite Integral Concepts. Universal Journal of Educational Research, 8(12B), 8313-8323. DOI: 10.13189/ujer.2020.082636.

Copyright $\bigcirc 2020$ by authors, all rights reserved. Authors agree that this article remains permanently open access under the terms of the Creative Commons Attribution License 4.0 International License

\begin{abstract}
The purpose of this study was to produce a comparison of the metacognition profile of male and female mathematics students in interpreting the definite integral concept. This type of research is an exploratory research with a qualitative approach, so that the researcher carries out a thorough and in-depth examination (explores) the subject of what is taught, done, written, and said during the research activity. The subjects of this study were mathematics students who had studied integral calculus, consisting of 1 male and 1 female. The main data collection of this research was obtained by using interview techniques. In addition, there are supporting data which is the result of the answers of research subjects in interpreting the integral concept of course. This study uses qualitative data analysis, consisting of data reduction, data presentation, and drawing conclusions. The results of this study show that male mathematics students can use metacognition knowledge (declarative, procedural, and conditional) and metacognition skills (planning, monitoring, and evaluation) in interpreting mathematical sentences into notation of definite integral concept. Meanwhile, female mathematics students are only able to use declarative and procedural knowledge, as well as planning and evaluation skills in interpreting mathematical sentences to notation of the definite integral concept. This study concluded that there are differences in the metacognition profile of male and female students in interpreting the definite integral concept.
\end{abstract}

Keywords Metacognition, Conceptual Interpretation, Male and Female, Mathematics Students

\section{Introduction}

Integral Calculus is one of the compulsory courses programmed by Mathematics Department students. This course is a collection of Scientific and Skill Courses which aim to strengthen the mastery and broaden the knowledge of skill competencies working society in accordance with the competitive and comparative advantages of implementing the study program concerned.

The integral calculus learning approach used by lecturers generally uses direct learning, namely student-centered learning. The benefit that arises from a student-centered pedagogical approach is the potential for increased conceptual understanding of the material studied by students [1]. Furthermore, Park and Traves stated that students can improve conceptual understanding without losing computational skills by learning mathematical principles through visual examples and deducing rules for themselves. This strategy is part of the student-centered learning approach, where students are actively involved in learning, while the lecturer acts as a facilitator [2].

In relation to understanding mathematical concepts, most research results have established that the concept of mental structure is related to intellectuality, not only with 
subject matter. The results showed that mental structures related to intellectuality can form mental concepts that regulate human experience and memory [3]. Therefore, conceptual change represents structural cognitive change, and does not merely add to change. Based on research in the field of cognitive psychology, the attention of research in education has shifted from content (eg mathematical concepts) to mental predicates, language, and pre-concepts [4]. Apart from this research, in general, lecturers and teachers who continuously present new concepts to students are as if they only convey knowledge by memorizing and remembering. As a result, students rarely solve math problems based on a concept. In relation to solving integral concept problems, students have difficulty expressing the initial idea of solving integral problems, and cannot explain the reasons for each step of solving them [5].

The description above shows that the presentation of mathematical concepts by memorizing and remembering does not raise students' awareness to understand a concept. This is in line with the results of previous research in the Mathematics department of Halu Oleo University, that the level of students' metacognitive awareness at the reflective level was only $38.64 \%$ [6]. This illustrates that the metacognition ability of Mathematics Department Students in solving mathematical concepts is still low. In addition, when comparing the metacognition awareness of male and female students at a relatively different reflective level, male students only reached $35.29 \%$, while female students only reached $40.74 \%$ [6].

This paper wants to see an overview of the metacognition profile of male and female mathematics students in understanding the integral concept of course. The metacognition profile in question is a natural and complete picture of a person's cognition that involves his own thinking in terms of using his knowledge, and the ability to plan and monitor his thought processes, as well as evaluate a person's thought processes and results when understanding a concept. This is in line with Koriat's opinion, that metacognition refers to what people know about cognition in general and about their cognitive processes, in particular, and how they use this knowledge to adjust their information processes and behavior [7]. While cognitive is the acquisition, regulation, and use of knowledge or processes that occur internally in the central nervous system when humans are thinking $[8,9]$.

To understand the concept of integrals, of course, we can use Bloom's theory developed by Anderson et al. [10], and Mayer [11]. Meanwhile, the profile of metacognition in understanding the integral concept is of course reviewed in two categories, namely metacognitive knowledge consisting of declarative knowledge, procedural knowledge and conditional knowledge [12, 13], and metacognition skills consisting of planning, monitoring and evaluation $[14,15]$.

The urgency of this study is that calculus learning will introduce students' metacognition earlier when teaching calculus concepts, especially in integral subjects. Thus, calculus learning emphasizes metacognition strategies in the learning process, so as to improve students' understanding of integral concepts. This is in line with the results of research by Salam et al. [16], that through behavior-based metacognition strategies, it can improve the results of metacognition awareness and understanding of hereditary concepts for mathematics education students. In addition, Lester said that the main goal of problem solving learning in mathematics is not only to equip students with a set of skills or processes, but rather to enable students to think about what they think [17]. Furthermore, the results of Lauren's [18] research show that the use of metacognition can be seen when students are asked to express mathematical ideas, or have group discussions. The result of research that has been done is the metacognition profile of prospective mathematics teachers in understanding the concept of integral calculus in terms of gender differences. The results obtained are that in the interpreting category, male math teacher candidates can only use declarative knowledge in understanding the integral concept of course. Meanwhile, female mathematics teacher candidates can use metacognition knowledge and metacognition skills in understanding integral concepts of course, except for conditional knowledge [19].

Based on this description, the problem of this research is how is the comparison between the metacognition profile of male and female mathematics students in interpreting the definite integral concepts?

\section{Materials and Methods}

\subsection{Types of Research}

This type of research is explorative with a qualitative approach. This exploratory study is intended to explore the metacognition of mathematics students in understanding the concept of integral calculus in order to obtain a large profile of student metacognition.

\subsection{Participants}

The subjects of this study were Mathematics Department students who were studying integral calculus, totaling 44 students. Based on the results of the mathematics ability test that was tested on 44 students, it was found that 14 students got a minimum score of 70 consisting of 11 female and 3 male. Of the 11 female selected 1 female, and 1 male was chosen from 3 males. The selection of the research subject was based on the highest score from the Mathematics Ability Test and considering outcome learning of student mathematics.

The steps for selecting the research subject are as 
follows:

- $\quad$ Select and assign students majoring in mathematics.

- Classifying students by gender and assigning male and female students.

- $\quad$ Provides tests of mathematical ability.

- $\quad$ Select 1 male and 1 female student who have high mathematical abilities and are able to communicate their opinions / thoughts orally or in writing.

\subsection{Data Collection}

There are two categories of data needed in this study, namely: First, quantitative data are the results of Mathematics Ability Tests (MAT) given to students of mathematics education that are used to determine the subject of research, and the results of a gender questionnaire to determine the type of gender. Second, qualitative data are used to answer all research questions. The main focus in this study is on the procedure for obtaining second category data according to the type of qualitative research.

As is usually the case with qualitative research, two types of instruments have been used to collect the two categories of data, namely the main instrument, the researcher himself, and the supporting instrument as a support consisting of: the Concept Understanding Test (CUT), Mathematics Ability Test (MAT), Interview Guidelines, and gender questionnaire.

The main data collection in this study was obtained using interview techniques. In addition, there are supporting data that is the result of written work of research subjects in solving the definite integral problems.

The interview was conducted by the researcher himself as a key instrument. Therefore the first and foremost activity carried out in the process of collecting research data is an interview. Interviews were conducted repeatedly to obtain sufficient and credible data to be processed according to the needs in order to answer research questions. In this interview activity, the researcher interviewed the Research Subject with the guidelines for the interview guidelines that had been prepared. Interview material concerns the subject's metacognition in understanding the concept of integral of course in depth. For this purpose, the assistive instrument used is the interview guide. The data obtained relating to this material is used to find the subject's metacognition profile in understanding the concept of definite integral. To obtain credible data, triangulation of data is needed, namely data validity checking techniques using other sources. Data triangulation used in this study is to use time triangulation.

\subsection{Data Analysis}

Analysis of the data of this study used qualitative data analysis. The process of data analysis follows the analysis model of Miles, Huberman, and Saldana [20] consisting of three activities that occur simultaneously, namely: (1) Data Condensation, (2) Presentation of data (Data Display), and (3) drawing conclusions (Conclusion Drawing/Verifications).

Data condensation refers to the process of selecting, focusing, simplifying, abstracting, and/or transforming data that approximates all parts of written field notes, interview transcripts, documents, and other empirical material. Presentation of data is a collection of compressed information that allows drawing conclusions and actions. Meanwhile, drawing conclusions are made based on the results of data processing based on research questions, namely how the comparison of metacognition profiles of male and female math students in interpreting the definite integral concepts. This stage also presented the results of a comparison of the metacognition profile of male and female subjects in understanding the concept of integral of course. The steps taken to draw conclusions are first, the initial conclusions put forward are still temporary, and will change if evidence is found to support the next stage of data collection. Second, verify initial conclusions, i.e. if strong evidence is found in the sense of being consistent with the conditions found when returning to the field, the conclusions obtained are credible conclusions.

\subsection{Research Procedure}

The research procedure can be seen in the flow chart in Figure 1 below: 


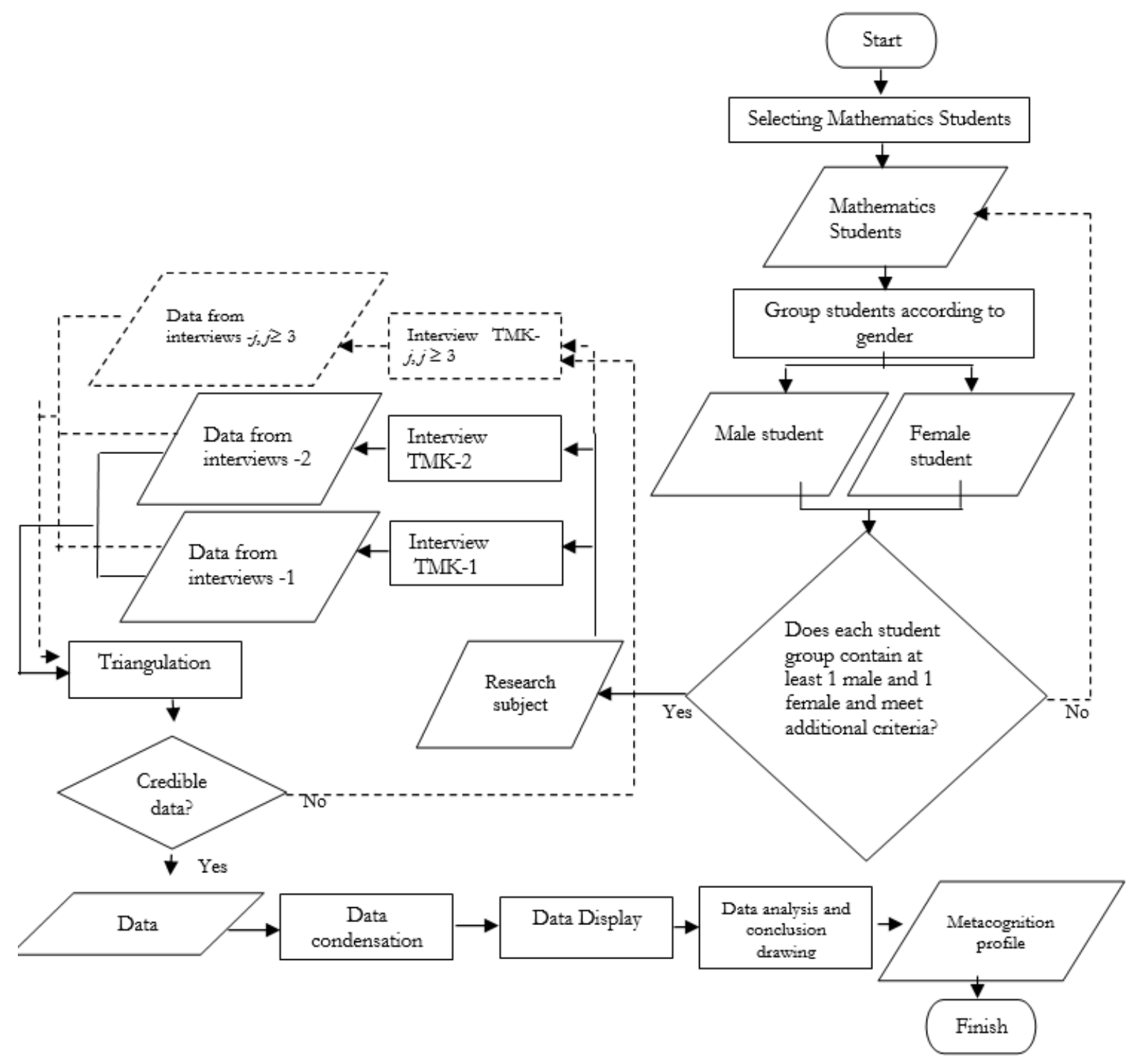

Figure 1. Research Procedure Flowchart

\section{Results}

The results of this study reveal the profile of the metacognition of male and female mathematics students in interpreting the definite integral concepts. To reveal the students' metacognition profile, first, seeing the understanding of male and female mathematics students about the definite integral concepts based on students' answers in completing the task of understanding the integral concepts. Second, through interviews, it can reveal students' metacognition in interpreting the definite integral concepts.

\subsection{Understanding of Male and Female Mathematics Students in Interpreting the Definite Integral Concepts}

The answers of male and female mathematics students in interpreting the integral concept can be seen in Table 1.
Table 1. Answers of male and female mathematics students in interpreting definite integral concepts

\begin{tabular}{|c|c|c|}
\hline \multirow{2}{*}{ Task questions } & \multicolumn{2}{|c|}{ Student Answers } \\
\hline & Male & Female \\
\hline Make a mathematical sentence & $=\int_{a}^{b} f(x) d x$ & $=\int_{a}^{b} f(x) d x$ \\
\hline
\end{tabular}

Based on the results of the students' answers in Table 3, male and female mathematics students can interpret mathematical sentences to calculate the area of an area in the form of certainly correct integral notation. 


\subsection{The Results of Interviewing Male Mathematics Students in Interpreting the Definite Integral Concepts}

a). Exposure to Male Metacognition Data in Interpreting the Definite Integral Concepts

Excerpts of the results of the first interview of male students in interpreting the concept of definite integral can be presented as follows:

\begin{tabular}{|c|c|}
\hline $\mathrm{ILM}_{1} \mathrm{O}_{1}$ & Make a mathematical sentence to calculate the area of the intended intergral area. \\
\hline $\mathrm{SLM}_{1} \mathrm{O}_{1}$ & The integral notation of the area of the integral is $A=\int_{a}^{b} f(x) d x$ \\
\hline $\mathrm{ILM}_{1} \mathrm{O}_{2}$ & What is the reason you write integral notation is certainly like that? \\
\hline $\mathrm{SLM}_{1} \mathrm{O}_{2}$ & $\begin{array}{l}\text { I mention integral notation of course, because based on my knowledge and experience since I was in high school studying } \\
\text { calculus that the form of integral notation is certainly like the notation put forward by Leibniz. }\end{array}$ \\
\hline $\mathrm{ILM}_{2} \mathrm{O}_{3}$ & What is the procedure for obtaining the definite integral notation? \\
\hline $\mathrm{SLM}_{2} \mathrm{O}_{3}$ & $\begin{array}{l}\text { The procedure for obtaining the definite integral notation is, the image of an integral region curve that is limited by the } \\
\text { function } f \text {, the } x \text {-axis at intervals }[\mathrm{a}, \mathrm{b}] \text { is partitioned for } \mathrm{n} \text { square lengths. Then, take a sample of the } i \text {-th partition, with width } \\
\Delta \mathrm{x}_{\mathrm{i}} \text { and length } f\left(\mathrm{x}_{\mathrm{i}}\right) \text { hence the area } \mathrm{L}=f\left(\mathrm{x}_{\mathrm{i}}\right) \Delta \mathrm{x}_{\mathrm{i}} \text {. Furthermore, with intervals }[\mathrm{a}, \mathrm{b}] \text { then the area is } \mathrm{L}=\sum_{i=1}^{n} f\left(x_{i}\right) \Delta x_{i} \text {. }\end{array}$ \\
\hline $\mathrm{ILM}_{2} \mathrm{O}_{4}$ & Is the specified area in accordance with the area of the integral curve in question? \\
\hline $\mathrm{SLM}_{2} \mathrm{O}_{4}$ & $\begin{array}{l}\text { Not yet, we still need to partition the interval }[\mathrm{a}, \mathrm{b}] \text { to be reduced to near zero so that the number of rectangles covering the } \\
\text { curve region approaches infinity. So, the area of the curve is } L=\lim _{|p| \rightarrow 0} \sum_{i=1}^{n} f\left(x_{i}\right) \Delta x_{i}=\int_{a}^{b} f(x) d x\end{array}$ \\
\hline $\mathrm{ILM}_{3} \mathrm{O}_{5}$ & Are there other procedures for defining integral notations of course besides using partitions at intervals [a,b]? \\
\hline $\mathrm{SLM}_{3} \mathrm{O}_{5}$ & Nothing, sir. \\
\hline $\mathrm{ILM}_{3} \mathrm{O}_{6}$ & Is there another notation of integral of course besides the notation mentioned above? \\
\hline $\mathrm{SLM}_{3} \mathrm{O}_{6}$ & Nothing, sir. \\
\hline $\mathrm{ILM}_{4} \mathrm{O}_{7}$ & Is the integral notation of course mentioned is correct? \\
\hline $\mathrm{SLM}_{4} \mathrm{O}_{7}$ & Yes sir, right \\
\hline $\mathrm{ILM}_{4} \mathrm{O}_{8}$ & What is your reason for saying true? \\
\hline $\mathrm{SLM}_{4} \mathrm{O}_{8}$ & I answer according to the definite integral definition (Basic Calculus Theorem), ie $\lim _{|p| \rightarrow 0} \sum_{i=1}^{n} f\left(x_{i}\right) \Delta x_{i}=\int_{a}^{b} f(x) d x$. \\
\hline $\mathrm{ILM}_{5} \mathrm{O}_{9}$ & What do you mean by notation $A=\int_{a}^{b} f(x) d x ?$ \\
\hline $\mathrm{SLM}_{5} \mathrm{O}_{9}$ & $\begin{array}{l}\text { This means that the area of the bounded function } f \text {, the } x \text {-axis at intervals [a, b] is integral to the function } f(x) \text { with the lower } \\
\text { limit } a \text { and the upper limit } b \text {. }\end{array}$ \\
\hline $\mathrm{ILM}_{5} \mathrm{O}_{10}$ & What is the hook element of the definite integral? \\
\hline $\mathrm{SLM}_{5} \mathrm{O}_{10}$ & Derivative and anti-derivative, sir. \\
\hline $\mathrm{ILM}_{5} \mathrm{O}_{11}$ & Are anti-derivatives the same as indefinite integrals? \\
\hline $\mathrm{SLM}_{5} \mathrm{O}_{11}$ & Yes sir, same. \\
\hline $\mathrm{ILM}_{5} \mathrm{O}_{12}$ & How is the definition of anti-derivative? \\
\hline $\mathrm{SLM}_{5} \mathrm{O}_{12}$ & $\begin{array}{l}\text { The definition of anti-derivative is that if we call } F(x) \text { is the anti-derivative of } f(x) \text {, it can be written that the integral of } f(x) \\
d x \text { is } F(x)+C \text {. }\end{array}$ \\
\hline $\mathrm{ILM}_{6} \mathrm{O}_{13}$ & Try to restate the notation to calculate the area of the integrated area that has been determined? \\
\hline $\mathrm{SLM}_{6} \mathrm{O}_{13}$ & The integral notation of the area of the integral is $A=\int_{a}^{b} f(x) d x$. \\
\hline $\mathrm{ILM}_{6} \mathrm{O}_{14}$ & Do you determine the definite integral notation feeling difficult? \\
\hline $\mathrm{SLM}_{6} \mathrm{O}_{14}$ & No difficulties, sir. \\
\hline
\end{tabular}


b). Data Analysis and Withdrawal of Male Metacognition Conclusions in Interpreting the Definite Integral Concepts

Based on data code $\mathrm{SLM}_{1} \mathrm{O}_{1}$ and $\mathrm{SLM}_{1} \mathrm{O}_{2}$, it shows that male students know integral notation based on their knowledge and experience since high school studying calculus so that they can write the definite integral notation. This means that male students are aware of mentioning and writing the interpretation of integral notation based on the area of the specified integral is $A=\int_{a}^{b} f(x) d x$, because based on his knowledge and experience since high school studying calculus, the form of the definite integral notation is like the notation put forward by Leibniz. It is concluded that male students use declarative knowledge in interpreting integral notation based on an area of integral is $A=\int_{a}^{b} f(x) d x$.

Data code $\mathrm{SLM}_{2} \mathrm{O}_{3}$ and $\mathrm{SLM}_{2} \mathrm{O}_{4}$, show that male mathematics students know the procedure for obtaining integral notation of course is from the image of the curve of the integral region that is limited by the function $f$, the $x$-axis at intervals $[\mathrm{a}, \mathrm{b}]$ can be partitioned as many as $\mathrm{n}$ squares. Then, sample the i-th partition, width $\Delta x_{\mathrm{i}}$ end lengthy $f\left(x_{\mathrm{i}}\right)$ hence the breadth $\mathrm{L}=f\left(x_{\mathrm{i}}\right) \Delta x_{\mathrm{i}}$. Furthermore, with intervals $[\mathrm{a}, \mathrm{b}]$ then the area is $\mathrm{L}=\sum_{i=1}^{n} f\left(x_{i}\right) \Delta x_{i}$.

Then, the partition of the interval $[a, b]$ is reduced to near zero so that the number of rectangles covers the curve region approaches infinity. Thus, the area of the curve is $L=\lim _{|p| \rightarrow 0} \sum_{i=1}^{n} f\left(x_{i}\right) \Delta x_{i}=\int_{a}^{b} f(x) d x$. It was concluded that male mathematics students use procedural knowledge in interpreting integral notation based on an area of integral.

Data code $\mathrm{SLM}_{3} \mathrm{O}_{5}$ and $\mathrm{SLM}_{3} \mathrm{O}_{6}$, show that male mathematics students mention that there is no other procedure for the defining of definite integral notations other than using partitions at intervals $[a, b]$, and the only integral notation based on an area of integral is $A=\int_{a}^{b} f(x) d x$. It was concluded that male mathematics students use conditional knowledge in interpreting integral notation based on an area of integral.

Data code $\mathrm{SLM}_{4} \mathrm{O}_{7}$ and $\mathrm{SLM}_{4} \mathrm{O}_{8}$, show that male mathematical students consciously plan the interpretation form of mathematical sentences to calculate the area of the intergral area that has been determined with definite integral notation based on a definite integral definition (Basic Calculus Theorem), namely $\lim _{|p| \rightarrow 0} \sum_{i=1}^{n} f\left(x_{i}\right) \Delta x_{i}=\int_{a}^{b} f(x) d x$. It was concluded that male mathematics students use planning skills in interpreting mathematical sentences to calculate the area of the integrated area that has been determined with the definite integral notation. In addition, male mathematics students when using planning skills in interpreting mathematical sentences calculate the area of an integrated area that has been determined with definite integral notation, using declarative knowledge, procedural knowledge, and conditional knowledge.

Data code $\mathrm{SLM}_{5} \mathrm{O}_{9}, \mathrm{SLM}_{5} \mathrm{O}_{10}, \mathrm{SLM}_{5} \mathrm{O}_{11}$, and $\mathrm{SLM}_{5} \mathrm{O}_{12}$, show that male math students consciously control the form of interpretation of mathematical sentences to calculate the area of an area that has been determined with the definite integral notation, by interpreting symbols $A=\int_{a}^{b} f(x) d x$ as the area of the bounded function $f$, the $x$-axis at intervals $[\mathrm{a}, \mathrm{b}]$ is integral to the function $f(x)$ with the lower limit $a$ and the upper limit $b$. Then, determine the hook element of a definite integral, that is, derivative and anti-derivative or indefinite integral. It was concluded that male mathematics students use monitoring skills in interpreting mathematical sentences to calculate the area of the integrated area that has been determined with the definite integral notation. In addition, male mathematics students when using monitoring skills in interpreting mathematical sentences calculate the area of the integrated area that has been determined with the definite integral notation, based on declarative knowledge, procedural knowledge, and conditional knowledge.

Data code $\mathrm{SLM}_{6} \mathrm{O}_{13}$, and $\mathrm{SLM}_{6} \mathrm{O}_{14}$, show that conscious male mathematics students have no difficulty mentioning the interpretation of mathematical sentences to calculate the area of the integrative area that has been determined with the definite integral notation. It is concluded that male mathematics students use the skill of evaluating in interpreting mathematical sentences to calculate the area of the integrated area that has been determined with the definite integral notation. In addition, male mathematics students when using evaluation skills in interpreting mathematical sentences calculate the area of integrated regions that have been determined with the definite integral notation, based on declarative knowledge, procedural knowledge, and conditional knowledge.

Based on the results of the interview, it can be seen that male mathematics students can use metacognition knowledge and skills in interpreting the definite integral concepts.

The metacognition profile of male mathematics students in interpreting the definite integral concepts above can be made in the form of a scheme like Figure 2.

The metacognition profile scheme of male mathematics students illustrates that male mathematical students use declarative, procedural, and conditional knowledge correctly in interpreting mathematical sentences to calculate the area of a given internal area with the definite integral notations. Likewise, male mathematical students use the skills to plan, monitor, and evaluate correctly in interpreting mathematical sentences to calculate the area of an integrated area that has been determined with the definite integral notation. In addition, male mathematics students use the skills of planning, monitoring, and evaluating in interpreting mathematical sentences to calculate the area of integrated area that has been determined with the definite integral notation based on declarative, procedural, and conditional knowledge. 


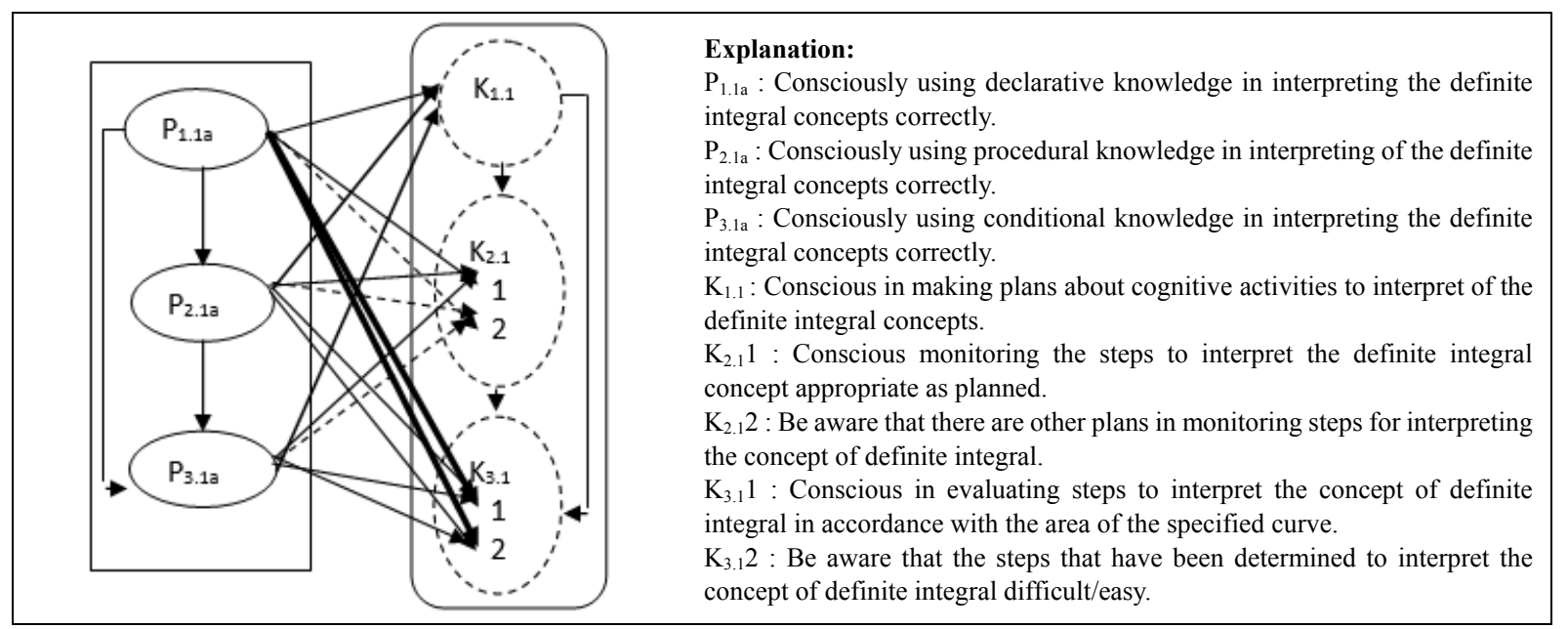

Figure 2. Schematic metacognition profile of male mathematics students in interpreting the definite integral concepts

\subsection{The Results of the Interviews of Female Mathematics Students in Interpreting the Definite Integral Concepts}

a). Exposure to Female Metacognition Data in Interpreting the Definite Integral Concepts

Excerpts of the results of the first interview of female students in interpreting the concept of definite integral can be presented as follows:

\begin{tabular}{|c|c|}
\hline $\mathrm{IPM}_{1} \mathrm{O}_{1}$ & Make a mathematical sentence to calculate the area of the intended intergral area. \\
\hline $\mathrm{SPM}_{1} \mathrm{O}_{1}$ & The integral notation of the area of the integral is $L=\int_{a}^{b} f(x) d x$ \\
\hline $\mathrm{IPM}_{1} \mathrm{O}_{2}$ & What is the reason you write integral notation is certainly like that? \\
\hline $\mathrm{SPM}_{1} \mathrm{O}_{2}$ & $\begin{array}{l}\text { Because the calculated area of the area where it is located at a certain interval, with a curve that limits it. Thus, the integral } \\
\text { notation of the curve can be written by using the integral of the } f(x) \text { function and still paying attention to its limits. }\end{array}$ \\
\hline $\mathrm{IPM}_{2} \mathrm{O}_{3}$ & What is the procedure for obtaining the definite integral notation? \\
\hline $\mathrm{SPM}_{2} \mathrm{O}_{3}$ & $\begin{array}{l}\text { The procedure for obtaining integral notation is, of course, the image of the curve of the integral region bounded by the } \\
\text { function } f \text {, the } \mathrm{x} \text {-axis at intervals [a, b] is partitioned for } \mathrm{n} \text { square lengths. Then, sample the i-th partition, width } \Delta \mathrm{x}_{\mathrm{i}} \text { and lengthy } \\
\mathrm{f}\left(\mathrm{x}_{\mathrm{i}}\right) \text { then the area is } \mathrm{L}=\mathrm{f}\left(\mathrm{x}_{\mathrm{i}}\right) \Delta \mathrm{x}_{\mathrm{i}} \text {. Furthermore, with intervals [a, b] then the area is } \mathrm{L}=\sum_{i=1}^{n} f\left(x_{i}\right) \Delta x_{i}{ }^{\cdot}\end{array}$ \\
\hline $\mathrm{IPM}_{2} \mathrm{O}_{4}$ & Is the specified area in accordance with the area of the integral curve in question? \\
\hline $\mathrm{SPM}_{2} \mathrm{O}_{4}$ & $\begin{array}{l}\text { No sir, because the partitions are large so there are parts of the curve that are not covered by the rectangle. So that you still need } \\
\text { to partition from the interval [a,b] reduced to near zero so that the number of rectangles that cover the curve area approaches } \\
\text { infinity. Thus, the area of the curve is } L=\lim _{|p| \rightarrow 0} \sum_{i=1}^{n} f\left(x_{i}\right) \Delta x_{i} \text {. Based on the definition of the number of Riemann then } \\
L=\int_{a}^{b} f(x) d x\end{array}$ \\
\hline $\mathrm{IPM}_{3} \mathrm{O}_{5}$ & Are there other procedures for defining the definite integral notations besides using partitions at intervals $[\mathrm{a}, \mathrm{b}]$ ? \\
\hline $\mathrm{SPM}_{3} \mathrm{O}_{5}$ & I don't know, sir. \\
\hline $\mathrm{IPM}_{3} \mathrm{O}_{6}$ & Is there another notation of the definite integral besides the notation mentioned above? \\
\hline $\mathrm{SPM}_{3} \mathrm{O}_{6}$ & That's the only notation that I know of, sir. \\
\hline $\mathrm{IPM}_{4} \mathrm{O}_{7}$ & Is the definite integral notation mentioned correct? \\
\hline $\mathrm{SPM}_{4} \mathrm{O}_{7}$ & Yes sir, right. \\
\hline $\mathrm{IPM}_{4} \mathrm{O}_{8}$ & What is your reason for saying true? \\
\hline $\mathrm{SPM}_{4} \mathrm{O}_{8}$ & I answered according to the definition of the number of Riemann, ie $\lim _{|p| \rightarrow 0} \sum_{i=1}^{n} f\left(x_{i}\right) \Delta x_{i}=\int_{a}^{b} f(x) d x$ \\
\hline $\mathrm{IPM}_{5} \mathrm{O}_{9}$ & What do you mean by notation $L=\int_{a}^{b} f(x) d x$ ? \\
\hline $\mathrm{SPM}_{5} \mathrm{O}_{9}$ & $\begin{array}{l}\text { This means that the area of the bounded function } f \text {, the } x \text {-axis at intervals [a, b] is integral to the function } f(x) \text { with the lower } \\
\text { limit } a \text { and the upper limit } b \text {. }\end{array}$ \\
\hline $\mathrm{IPM}_{5} \mathrm{O}_{10}$ & What is the hook element of the definite integral? \\
\hline $\mathrm{SPM}_{5} \mathrm{O}_{10}$ & Don't know, sir. \\
\hline $\mathrm{IPM}_{6} \mathrm{O}_{11}$ & Try to restate the notation to calculate the area of the integrated area that has been determined? \\
\hline $\mathrm{SPM}_{6} \mathrm{O}_{11}$ & The integral notation of the area of the integral is $L=\int_{a}^{b} f(x) d x$. \\
\hline $\mathrm{IPM}_{6} \mathrm{O}_{12}$ & Do you determine the definite integral notation feeling difficult? \\
\hline $\mathrm{SPM}_{6} \mathrm{O}_{12}$ & No difficulties, sir. \\
\hline
\end{tabular}


b). Data Analysis and Withdrawal of Female Metacognition Conclusions in Interpreting the Definite Integral Concepts

Based on data code $\mathrm{SPM}_{1} \mathrm{O}_{1}$ and $\mathrm{SPM}_{1} \mathrm{O}_{2}$, it shows that female students know integral notation based on their knowledge and experience that what is calculated is the area where it is located at a certain interval, with a curve that limits it. Thus, the integral notation of the curve can be written by using the integral of the $f(x)$ function and still paying attention to its limits. It was concluded that female students used declarative knowledge in interpreting an area of the curve with the definite integral notation is $L=\int_{a}^{b} f(x) d x$.

Data code $\mathrm{SPM}_{2} \mathrm{O}_{3}$ and $\mathrm{SPM}_{2} \mathrm{O}_{4}$, show that female mathematics students know the procedure for obtaining integral notation of course is from the image of the integral region curve that is limited by the function $f$, $x$-axis at intervals $[\mathrm{a}, \mathrm{b}]$ can be partitioned as many as $\mathrm{n}$ squares. Then, sample the i-th partition, width $\Delta x_{\mathrm{i}}$ and lengthy $f\left(x_{\mathrm{i}}\right)$ then the area of the curve is $L=f\left(x_{\mathrm{i}}\right) \Delta x_{\mathrm{i}}$. Furthermore, if the area at interval $[a, b]$ then the area to calculate the area of integrated regions $f\left(x_{\mathrm{i}}\right)$ then the area of the curve is $L=f\left(x_{\mathrm{i}}\right) \Delta x_{\mathrm{i}}$. Furthermore, if the area at interval $[\mathrm{a}, \mathrm{b}]$ then the area is $\mathrm{L}=\sum_{i=1}^{n} f\left(x_{i}\right) \Delta x_{i}$. Then, because the partitions are large, some parts of the curve are not covered by the rectangle. So that you still need to partition from the interval $[a, b]$ reduced to near zero so that the number of rectangles cover the curve area approaches infinity. Thus, the area of the curve is $L=\lim _{|p| \rightarrow 0} \sum_{i=1}^{n} f\left(x_{i}\right) \Delta x_{i}$. Based on the definition of the number of Riemann, the area of the curve is $L=\int_{a}^{b} f(x) d x$. It was concluded that female mathematics students used procedural knowledge in interpreting the area of the curve into the definite integral notation.

Data code $\mathrm{SPM}_{3} \mathrm{O}_{5}$ and $\mathrm{SPM}_{3} \mathrm{O}_{6}$, show that female math students do not know yet determine other procedures for defining the definite integral notations, and do not yet know that there are other notations besides the definite integral notations $L=\int_{a}^{b} f(x) d x$. It is concluded that female mathematics students have not used conditional knowledge in interpreting the area of the curve into the definite integral notation.

Data code $\mathrm{SPM}_{4} \mathrm{O}_{7}$ and $\mathrm{SPM}_{4} \mathrm{O}_{8}$, show that female mathematics students consciously plan the interpretation of mathematical sentences to calculate the area of the integrated area that has been determined with the definite integral notation based on the definition of the number Riemann, namely $L=\lim _{|p| \rightarrow 0} \sum_{i=1}^{n} f\left(x_{i}\right) \Delta x_{i}=\int_{a}^{b} f(x) d x$. It was concluded that female mathematical students used planning skills in interpreting mathematical sentences to calculate the area of integrated regions that had been determined with the definite integral notation. In addition, female mathematics students when using planning skills in interpreting mathematical sentences have been determined with the definite integral notation, using declarative knowledge, and procedural knowledge.

Data code $\mathrm{SPM}_{5} \mathrm{O}_{9}$, and $\mathrm{SPM}_{5} \mathrm{O}_{10}$, show that female math students consciously mention the meaning of integral notation of course is the area of the bounded function $f$, the $x$-axis at intervals [a, b] is integral to the function $f(\mathrm{x})$ with the lower limit $a$ and the upper limit $b$. However, it has not been able to mention the related elements of the integral of course. It was concluded that female mathematics students have not used monitoring skills in interpreting mathematical sentences to calculate the area of the integrated area that has been determined with the definite integral notation.

Data code $\mathrm{SPM}_{6} \mathrm{O}_{11}$, and $\mathrm{SPM}_{6} \mathrm{O}_{12}$, show that conscious female math students have no difficulty mentioning interpretations of mathematical sentences to calculate the area of a predetermined curve area with the definite integral notation. It was concluded that female mathematical students used evaluating skills in interpreting mathematical sentences to calculate the area of integrated area that had been determined with the definite integral notation. In addition, female mathematics students when using evaluation skills in interpreting mathematical sentences to calculate the area of intergral area that has been determined with the definite integral notation, based on declarative knowledge, and procedural knowledge.

Based on the results of the interview, it can be seen that female mathematics students can only use declarative and procedural knowledge in interpreting integral concepts of course. Similarly, female mathematics students can only use planning and evaluation skills in interpreting the definite integral concepts.

The metacognition profile of female mathematics students in interpreting the definite integral concepts above can be made in the form of a scheme like Figure 3. 


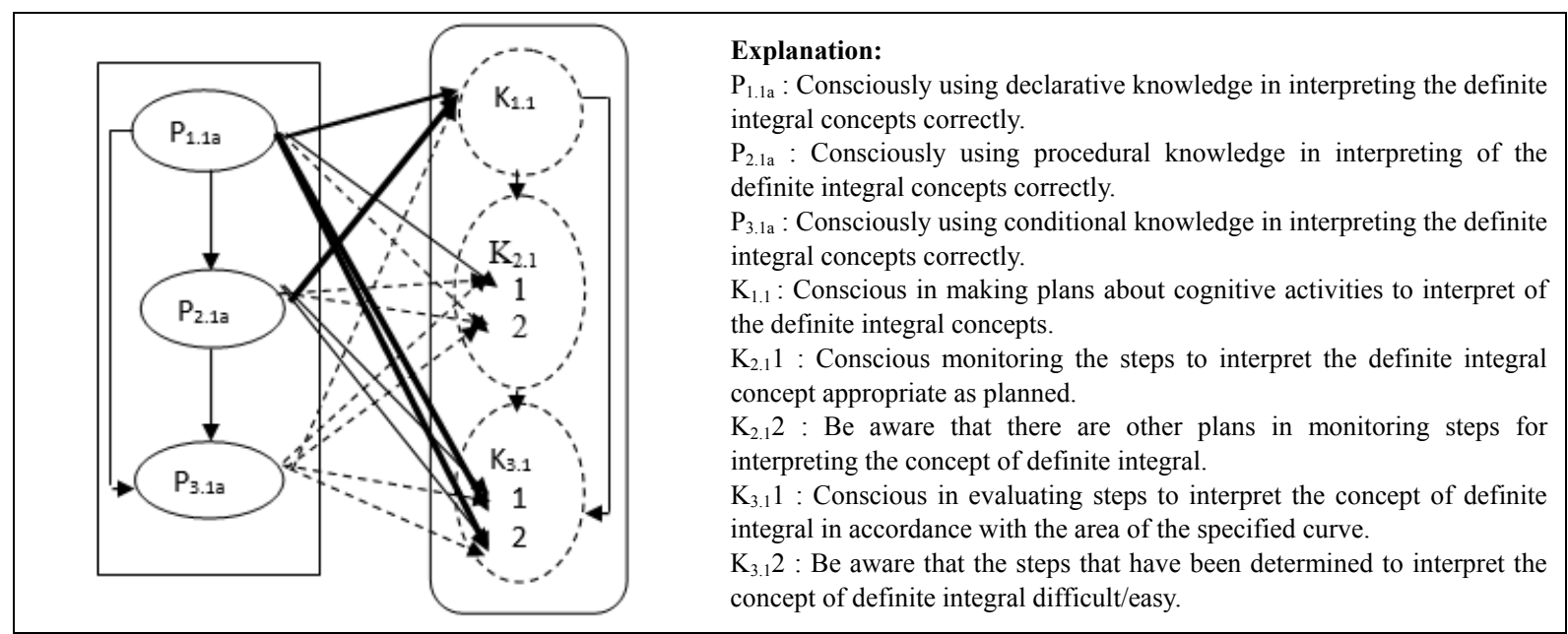

Figure 3. Schematic metacognition profile of female mathematics students in interpreting the definite integral concepts

The metacognition profile scheme of female mathematics students illustrates that female mathematical students use declarative and procedural knowledge correctly in interpreting mathematical sentences to calculate the area of the integrated area that has been determined with the definite integral notation. Likewise, female mathematics students use the skills of planning and evaluating correctly in interpreting mathematical sentences to calculate the area of the integrated area that has been determined with the definite integral notation. In addition, female mathematics students use planning and evaluating skills in interpreting mathematical sentences to calculate the area of an integrated area that has been determined with the definite integral notation based on declarative and procedural knowledge. However, female mathematics students do not use conditional knowledge and monitoring skills in interpreting mathematical sentences to calculate the area of the integrated area that has been determined with the definite integral notation.

\section{Discussion}

The results of the above study indicate that there are differences in the metacognition profiles between male and female math students in interpreting certain integrals. This is consistent with the opinion of Spelke [21] that between men and women show a somewhat different cognitive profile. Furthermore, male mathematical students can explain the reasons and procedures for getting naturally defined notation through the Riemann number approach. While female mathematics students are only able to write integral notations based on the Riemann number approach, but cannot explain the reasons and procedures for obtaining definite integral notations. This means that male students can analyze the area of the curve to get integral notation. Thus, the metacognition profile of male students is better than female students. This is in accordance with research of Yang that male are better than female in constructing and using theories [22]. Likewise, the results of the study by Pathuddin et al. [23] that male students with independent cognitive styles, tendencies to have structured and well-organized knowledge in proposing problem solving and can rearrange new information and relate it to the knowledge they have. This is in accordance with the opinion of Casey [24], and Maccoby \& Jacklyn [25] that groups of boys rely on spatial strategies when completing mental rotation tasks, while groups of girls tend to use verbal strategies to accomplish this task. The difference in metacognition between men and women is influenced by learning strategies.

This is in line with the results of research Callan et al. [26] that there are significant differences between how men and women utilize learning and metacognitive strategies. In addition, the results of Bahrami \& Yousefi's research [27] show that a significant difference was observed between girls and boys in thinking anxiety (health anxiety, social anxiety, and meta-worry). Thoughts of anxiety affect female more than male; they have more metacognitive beliefs about uncontrolled worries and believe that worries should be avoided. On the other hand, positive beliefs in worries are more common in girls and punishment and meta-worry are implemented as control strategies in female more than male.

However, the results of this study are somewhat different from the results of research conducted on prospective mathematics teacher students about the metacognition profile of prospective teacher students in interpreting the integral concepts of course. Prospective female mathematics teachers can explain the reasons or procedures for obtaining integral notation of course through the Riemann number approach. While male teacher candidates can only write integral notations of course, he cannot explain the reasons or procedures for obtaining definite integral notations [19]. This shows that in general, male and female students do not show 
significant differences in understanding mathematical concepts. This is in line with several studies finding that men do not outperform women in involving knowledge of procedures and algorithms, but outperform in problem solving starting from high school [28].

The difference between the two research results above, is possible for differences in the initial ability of students who enter each department both mathematics and mathematics education. This is consistent with the preliminary study in this study that the metacognition awareness of male mathematics students is higher than female students. In addition, differences in Student metacognition are caused by declarative knowledge factors. This is consistent with the results of research by Schneider \& Artelt [29] that there is a substantially declarative metacognition impact on mathematical performance (about $15-20 \%$ of the general variant). Another factor is solving contextual mathematical problems. This is in line with the results of Anggo et.al [30] research that one of the factors contributing to contextual mathematics problems, the subject must translate contextual problem situations into mathematical models to use formal mathematical settlement procedures. In addition to the declarative knowledge factor, there is also a qualitative shift in reflection aiming at a person's cognitive processes. This is consistent with the results of research by Volodymyr et al. [31] that experiences of various learning activities and the changes that accompany them in the cognitive realm initiate the process of developing learning abilities and form "competencies to acquire and renew competencies".

\section{Conclusion and Suggestion}

Based on the results of the research and discussion above, it can be concluded that:

There is a difference in Metacognition profiles between male and female mathematics students in interpreting the definite integral concepts. Male mathematics students can use declarative, procedural, and conditional knowledge in interpreting mathematical sentences to calculate the area of an integrated area that has been determined with a definite integral notation. Likewise, male mathematics students use the skills of planning, monitoring, and evaluating in interpreting mathematical sentences to calculate the area of an integrated area that has been determined with the definite integral notation. Whereas female mathematics students are only able to use declarative knowledge, procedural, and planning skills, evaluating the nature of interpreting mathematical sentences to calculate the area of an integrated area that has been determined with the definite integral notation.

It is expected that lecturers as instructors in integral calculus should always practice their students' knowledge and metacognitive skills in understanding or doing assignments. Because besides adding to the metacognitive activities of students when understanding a concept, it can also increase their understanding of the concept to be used in solving mathematical problems.

\section{Acknowledgements}

The author thanks the Chair of the Department of Mathematics at Universitas Halu Oleo, for giving us permission to conduct research on the students he leads. The author also thanks the mathematics students at Universitas Halu Oleo for giving a positive response to the questions of our research instruments so that the results of this study can be realized.

\section{REFERENCES}

[1] D. Tall. "The transition to formal thinking in mathematics." Mathematics Education Research Journal Vol. 20, No. 2, pp. 5-24, 2008. https://link.springer.com/journal/13394/volume s-and-issues.

[2] G. O'Neill, and T. McMahon."Student-centred learning: What does it mean for students and lecturers", 2005. http://www.aishe.org/ readings/2005-1/.

[3] R. Bartsch. "Dynamic Conceptual Semantics a Logico-Philosophical Investigation Into Concept Formation and Understanding", 1998. https://philpapers.org/rec/BARD CS-2.

[4] M. Ben-Hur. "Concept-rich mathematics instruction: Building a strong foundation for reasoning and problem solving." ASCD, 2006.

[5] U. Rahim, and L. Misu, "The resolution integral approach to metacognition in math education student of Halu Oleo University." International Journal of Education and Research, Vol. 3, No. 8, pp. 151-158, 2015. https://www.ijern.com/ index.php.

[6] L. Misu, I. K. Budayasa, A. Lukito, and Rosdiana. "Comparison of Metacognition Awareness of Mathematics and Mathematics Education Students Based on the Ability of Mathematics." International Journal of Trends in Mathematics Education Research, Vol. 2, No. 3, pp. 124-127, 2019. https://doi.org/ 10.33122/ijtmer.v2i3.118.

[7] C. Goh. "Metacognitive instruction for second language listening development: Theory, practice and research implications." RELC journal, Vol. 39, No. 2, pp. 188-213, 2008. DOI: $10.1177 / 0033688208092184$.

[8] R.M. Gagne. "Some issues in the psychology of mathematics instruction." Journal for Research in mathematics education, Vol. 14, No. 1, pp. 7-18, 1983. https://www.jstor.org/stable/ 748793,. DOI: $10.2307 / 748793$.

[9] U. Neisser. "Cognition and reality. Principles and implication of cognitive psychology." San Francisko: WH Freeman and Company, 1976.

[10] L.W. Anderson, and B.S.Bloom. “A taxonomy for learning, 
teaching, and assessing: A revision of Bloom's taxonomy of educational objectives." Longman, 2001.

[11] R. E. Mayer. "The promise of educational psychology: Teaching for meaningful learning." Vol. 2. Prentice hall, 2002 .

[12] J.H. Flavell. "Metacognition and cognitive monitoring: A new area of cognitive-developmental inquiry." American psychologist, Vol. 34, No. 10, pp. 906-911, 1979. https://doi.org/10.1037/0003-066X.34.10.906.

[13] W. Pierce. "Metacognition: Study Strategies, Monitoring, and Motivation. A greatly expanded text version of a workshop presented November 17, 2004, at Prince George's Community College.", 2004.

[14] T.L. Dawson. "Metacognition and learning in adulthood." Prepared in response to tasking from ODNI/CHCO/IC Leadership Development Office, Developmental Testing Service, $L L C, 2008$

[15] J.A. Livingston. "Metacognition: An Overview.", EDUCATIONAL RESOURCES INFORMATION CENTER (ERIC), 2003. https://eric.ed.gov/?id=ED474273.

[16] M. Salam, L. Misu, U. Rahim, N. Hindaryatiningsih, and A. Ghani. "Strategies of Metacognition Based on Behavioural Learning to Improve Metacognition Awareness and Mathematics Ability of Students." International Journal of Instruction, Vol. 13, No. 2 pp. 61-72, 2020. https://doi.org/ $10.29333 /$ iji.2020.1325a.

[17] M. Anggo. "Pelibatan metakognisi dalam pemecahan masalah matematika." Edumatica: Jurnal Pendidikan Matematika, Vol. 1, No. 1, pp. 25-32, 2011. https://online journal.unja. ac.id/edumatica/oai.

[18] T. Laurens. "Penjenjangan metakognisi siswa yang valid dan reliabilitas." Jurnal Pendidikan dan Pembelajaran, Vol. 17, No. 2, pp. 201-211, 2010. http://journal.um.ac.id/index.php/ pendidikan-danpembelajaran/article/view/3212.

[19] L. Misu, I. K. Budayasa, and A. Lukito. "Profile of metacognition of mathematics pre-service teachers in understanding the concept of integral calculus with regard gender differences." In Journal of Physics: Conference Series, vol. 947, No. 1, p. 012057. IOP Publishing, 2018. https://doi.org/10.1088/ 17426596/ 947/1/012057.

[20] M.B. Miles, A. M. Huberman, and J. Saldaña. "Qualitative data analysis: A methods sourcebook. 3rd." 2014.

[21] E.S. Spelke. "Sex differences in intrinsic aptitude for mathematics and science?: a critical review." American Psychologist, Vol. 60, No. 9, pp. 950-958, 2005. https:// doi.org/10.1037/0003-066X.60.9.950.
[22] C. Piraksa, N. Srisawasdi, and R. Koul. "Effect of gender on student's scientific reasoning ability: A case study in Thailand." Procedia-Social and Behavioral Sciences, Vol. 116, pp. 486-491, 2014. https://www.sciencedirect.com/ journal/procedia-social-and-behavioralsciences/vol/116/sup $\mathrm{pl} / \mathrm{C}$.

[23] Pathuddin, I.K. Budayasa, \& A. Lukito. "Metacognitive activity of male students: difference field independent-dependent cognitive style". In Journal of Physics: Conference Series, Vol. 1218, No. 1, p. 012025). IOP Publishing, 2019. https://doi:10.1088/1742-6596/1218/ $1 / 012025$.

[24] M. B. Casey, L. N. Ronald, and P. Elizabeth. "Spatial-mechanical reasoning skills versus mathematics self-confidence as mediators of gender differences on mathematics subtests using cross-national gender-based items." Journal for research in mathematics education, pp. 28-57, 2001. https://www.jstor.org/stable/ 749620.

[25] E.E Maccoby, and C.N. Jacklin. "The psychology of sex differences." Vol. 2. Stanford University Press, 1978. https://books.google.co.id/books?id=2g63eUFP7VkC.

[26] G.L. Callan, G.J. Marchant, W.H. Finch, and R.L. German. "Metacognition, strategies, achievement, and demographics: Relationships across countries." Educational Sciences: Theory \& Practice, Vol. 16, No. 5, pp. 1485-1502, 2016. https://doi.org/10.12738/estp. 2016.5.0137.

[27] F. Bahrami, and N. Yousefi. "Females are more anxious than males: a metacognitive perspective." Iranian journal of psychiatry and behavioral sciences, Vol. 5, No. 2, pp. 83-90, 2011.https://sites.kowsarpub.com/ijpbs/articles/2979.html.

[28] J.S. Hyde, E. Fennema, and S.J. Lamon. "Gender differences in mathematics performance: A meta-analysis." Psychological bulletin, Vol. 107, No. 2, pp. 139-155, 1990. https://doi.org/10.1037/0033-2909.107.2.139.

[29] W. Schneider, and C. Artelt. "Metacognition and mathematics education." ZDM, Vol. 42, No. 2, pp. 149-161, 2010.https://link.springer.com/journal/11858/volumes-andissues/42-2.

[30] M. Anggo, Suhar, \& Y.E.Y. Kansil. "Student's Metacognitive Activities in Solving Mathematics Problems". In 1st International Conference on Advanced Multidisciplinary Research (ICAMR 2018). Atlantis Press, pp. 16-20, 2019. http://creativecommons.org/licenses/by-nc $14.0 \%$

[31] L.G. Volodymyr, I.K. Nataliia, S.V. Albul, and T.S. Ye. "Cognitive and metacognitive aspects of the development of lifelong learning competencies in law students". International Journal of Cognitive Research in Science, Engineering and Education, Vol. 8 No. 2, pp. 1-14, 2020. www.ijcress.com. 